\title{
Hashimoto's encephalopathy in the setting of subclinical hypothyroidism
}

\author{
Vasile M Bota, Dominic F Corrigan
}

\begin{abstract}
Introduction: We describe the occurrence of Hashimoto's encephalopathy in the setting of subclinical hypothyroidism. We report the unusual presentation of a 62-year-old female with subclinical hypothyroidism and severe cognitive impairment. Pertinent literature is discussed. Case Report: In September 2008 the patient experienced episodic dizziness and gradual cognitive impairment. An outpatient neurological evaluation was non diagnostic. In January 2009 she experienced severe gait imbalance, dysarthria and handwriting change. Despite partial improvement, three months later her symptoms recurred accompanied by confusion, amnesia and generalized tonic-clonic seizures. She underwent complete neurologic investigations without establishment of a clear diagnosis. Subsequent testing for antithyroglobulin antibody and antithyroid peroxidase antibody were $2020.4 \mathrm{IU} / \mathrm{ml}$ and $186.8 \mathrm{IU} / \mathrm{ml}$ respectively (reference range: $0-60 \mathrm{IU} / \mathrm{ml}$ for
\end{abstract}

Vasile M Bota ${ }^{1}$, Dominic F Corrigan ${ }^{2}$

Affiliations: ${ }^{1}$ Internal Medicine Resident, Boston University School of Medicine and Roger Williams Medical Center, Providence, RI; ${ }^{2}$ Associate Clinical Professor of Medicine, Division of Endocrinology, The Warren Alpert Medical School of Brown University and Rhode Island Hospital, Providence, RI.

Corresponding Author: Vasile M Bota, Mailing address: Roger Williams Medical Center, Department of Medical Education, 825 Chalkstone Ave, Providence RI, 02908; Phone: 401-456-2000 Fax: 401-456-6809; Email: vmbota@gmail.com, vbota@rwmc.org

Received: 03 February 2011

Accepted: 27 March 2011

Published: 30 April 2011 both tests). A diagnosis of Hashimoto`s encephalopathy was made and she was started on glucocorticoids with a rapid clinical response. She was switched to oral prednisone, with a slow taper. Conclusion: Hashimoto`s encephalopathy is an association of encephalopathy with elevated serum antithyroid antibody levels and has a favorable clinical response to glucocorticoid therapy. Hashimoto's encephalopathy should be suspected in every patient with encephalopathy without detectable cause, especially in the setting of an underlying thyroid abnormality.

Keywords: Hashimoto's encephalopathy, Subclinical hypothyroidism, Hashimoto, Corticosteroid responsive encephalopathy, Autoimmune thyroiditis, Encephalopathy

$* * * * * * * * *$

Bota VM, Corrigan DF. Hashimoto's encephalopathy in the setting of subclinical hypothyroidism. International Journal of Case Reports and Images 2011;2(4):19-22.

$* * * * * * * * *$.

doi:10.5348/ijcri-2011-04-30-CR-5

\section{INTRODUCTION}

In 1966, Lord Brain described the case of a 40-yearold man with history of autoimmune thyroiditis who presented with episodes of hemiplegia, confusion and visual disturbances. He was the first one to suggest that antibody studies might be helpful in the diagnosis of unexplained encephalopathy. Since then the association with serologic evidence of thyroid autoimmunity has been increasingly recognized as a 
definite clinical association and may present as a complex diagnostic and therapeutic problem. The lack of clear evidence of the pathogenic role of the thyroid antibodies and their high prevalence rate in the normal population continues to be a source of continuous controversy, but the dramatic response to treatment in patients otherwise without a diagnostic answer warrants more research and more awareness inside the medical community.

We report a case of Hashimoto's encephalopathy in a patient with subclinical hypothyroidism who responded to high dose glucocorticoid treatment and provide a brief review of the entity.

\section{CASE REPORT}

A 62-year-old female with a past medical history of hypertension and hypercholesterolemia was diagnosed with subclinical hypothyroidism in 1999. At that time a decision was made to monitor her clinically and biochemically without treatment.

In September 2008 she noticed episodic dizziness and gradual cognitive impairment. An outpatient neurological evaluation was non-diagnostic. In January 2009 she presented to hospital with severe gait imbalance, motor coordination issues, executive dysfunction, dysarthric speech, handwriting changes and episodic tremor. She partially improved with supportive therapy only, but three months later her symptoms recurred with increased confusion, amnesia and two generalized tonic-clonic seizures with postictal confusion. She underwent complete neurological investigations including CT and MRI of the brain, EEG and CSF analysis without establishment of a clear diagnosis. Hemogram and liver and kidney function measurements were unremarkable. Subsequent testing for antithyroglobulin antibody and antithyroid peroxidase antibody were 2020.4 IU/ml and 186.8 $\mathrm{IU} / \mathrm{ml}$ respectively (reference range $0-60 \mathrm{IU} / \mathrm{ml}$ for both tests). Her 14-3-3 protein (a non-specific marker of central nervous system neuronal injury which is a highly sensitive and specific for Creutzfeldt-Jakob disease) was not elevated. TSH was $4.86 \mathrm{uU} / \mathrm{mL}$ (5.97 $\mathrm{uU} / \mathrm{mL}$ in January 2009), not on levothyroxine treatment (Table 1). A diagnosis of Hashimoto's encephalopathy was made and she was started on $1 \mathrm{gm}$ methylprednisolone, administered intravenously daily over three days. There was a rapid clinical response.

She was switched to oral prednisone starting at 60 mg daily, with a slow taper. She relapsed in August 2009 but responded well to a dose increase. She was off prednisone through April 2010 but EEG testing showed nonspecific abnormalities and shortly thereafter the patient experienced recurrent dizziness and headaches. Glucocorticoid treatment was restarted and she is currently asymptomatic while on prednisone $10 \mathrm{mg}$ PO every other day. Interestingly, her anti-TPO antibody has declined to $18 \mathrm{U} / \mathrm{ml}$, which is within the normal limits, although thyroglobulin autoantibodies are still elevated. She continues on phenytoin $150 \mathrm{mg}$ daily (initiated after the first seizure episode), vitamin D, alendronate, lisinopril, aspirin, fluoxetine and atorvastatin.

\section{DISCUSSION}

Hashimoto's encephalopathy is an association of encephalopathy, elevated serum antithyroid antibody levels and often a favorable clinical response to glucocorticoid therapy. Approximately $35 \%$ of patients have subclinical hypothyroidism; 30\% are euthyroid at presentation; and 20\% are overtly hypothyroid [1]. Twenty-five percent of patients may only have a single positive antibody present [1]. Brain CT or MRI shows nonspecific abnormalities in half of the patients [1]. EEG is abnormal in 98\%, often with diffuse slow wave activity or evidence of seizure like activity [1]. Clinically, the key feature is an encephalopathy [2] and the course is often relapsing-remitting [1]. A progressive disorder characterized by dementia and psychiatric features also has been recognized. Seizures occur in $66 \%$ of patients and myoclonus in $38 \%$ [1]. Stroke-like episodes or psychosis are also frequent [1, 2].

The etiology, pathogenesis and histopathologic characteristics of Hashimoto's encephalopathy are not as yet elucidated and the role played by antithyroid antibodies is unknown and controversial. Current hypotheses include autoimmune vasculitis, autoimmune reaction against common brain-thyroid antigens, demyelinizing processes with disseminated encephalomyelitis, global cerebral hypoperfusion, brain edema or direct toxic effect by excessive thyrotropin-releasing hormone output [3]. Brain biopsy findings of perivascular lymphocytic infiltration and the response to steroids have raised the question of a cerebral vasculitis.

Antithyroid antibodies have been linked to other neurological conditions like neuropathy, myopathy, depression and dementia but their high incidence in the general population makes these other association questionable [1].

A new autoantibody directed against the amino $\left(\mathrm{NH}_{2}\right)$-terminal of a-enolase (NAE) has a high prevalence (68\%) and high specificity for patients with Hashimoto's encephalopathy but its role in the pathogenesis is not yet elucidated [4]. In the future this might play a role in the diagnosis of the disease.

An Italian study published in 2008 demonstrated that serum and CSF IgG from six patients with Hashimoto's encephalopathy has a high reactivity to CNS antigens, binding in more than 50\% of the cases with 3 particular spots identified as dimethylarginase-I (DDAHI) and aldehyde reuctase I (AKRIAI), with DDAHI presenting in two isoforms [5]. But the reactivity to the autoantigen $\alpha$-enolase was low and only present in 2/6 patients with $\mathrm{HE}$ and $1 / 16$ control patients [5]. The same study failed to prove any 
Table 1: Summary of laboratory and imaging investigations

\begin{tabular}{|c|c|c|c|c|c|}
\hline & $\begin{array}{l}\text { January } \\
2009\end{array}$ & April 2009 & May 2009 & April 2010 & $\begin{array}{l}\text { June } \\
2010\end{array}$ \\
\hline $\begin{array}{l}\text { TSH } \\
(0.35-5 \cdot 50) \mathrm{uIU} / \mathrm{ml}\end{array}$ & $5 \cdot 97$ & 4.86 & - & 6.13 & - \\
\hline $\begin{array}{l}\mathrm{FT} 4 \\
(0.80-1.80) \mathrm{ng} / \mathrm{dl}\end{array}$ & - & - & - & 0.96 & - \\
\hline $\begin{array}{l}\text { Thyroglobulin } \\
\text { Autoantibodies (o-6o) U/ml }\end{array}$ & - & 2020.4 & - & 12274.9 & 3000 \\
\hline $\begin{array}{l}\text { Antithyroid peroxidase } A B \\
(1-60) \mathrm{IU} / \mathrm{m}\end{array}$ & - & 186.8 & - & $145 \cdot 3$ & 18 \\
\hline Imaging & - & $\begin{array}{l}\text { CT of the brain - no } \\
\text { evidence of an acute } \\
\text { intracranial process } \\
\text { MRI of the brain with } \\
\text { gadolinium - normal }\end{array}$ & - & - & - \\
\hline EEG interpretation & - & $\begin{array}{l}\text { Mild slowing in the } \\
\text { background rhythms } \\
\text { and right temporal } \\
\text { sharp waves }\end{array}$ & $\begin{array}{l}\text { Mild diffuse } \\
\text { encephalopathy } \\
\text { and a right } \\
\text { temporal } \\
\text { epileptogenic } \\
\text { focus }\end{array}$ & $\begin{array}{l}\text { Left greater than right } \\
\text { temporal region } \\
\text { abnormality with } \\
\text { continued evidence for } \\
\text { an epileptogenic focus }\end{array}$ & - \\
\hline CSF testing & - & $\begin{array}{l}\text { Protein } 92 \mathrm{mg} / \mathrm{dl} \\
\text { (normal range 15-45) } \\
\text { Cryptococcal, } \\
\text { Ehrlichia, RPR, } \\
\text { VDRL, Babesia, Lyme } \\
\text { - negative } \\
\text { Cultures and Gram - } \\
\text { negative }\end{array}$ & - & - & - \\
\hline Other tests & - & $\begin{array}{l}\text { EBV, CMV, Hepatitis } \\
\text { panel, Varicella, } \\
\text { Enterovirus, HIV, } \\
\text { Herpes - negative } \\
\text { Antibody panel for } \\
\text { paraneoplastic } \\
\text { disease - negative }\end{array}$ & - & - & - \\
\hline
\end{tabular}

specific binding between anti-thyroglobulin IgG to a CNS structure. [5] A single study demonstrated that both Hashimoto's encephalopathy sera and anti-TPO monoclonal antibodies (mAb) were able to bind cerebellar cells expressing glial fibrillary acid protein using immunofluorescence assay of monkey cerebellum sections [6]. Normal human astrocytes from primary cultures also reacted with anti-TPO mAb [6].

The brisk clinical improvement that often occurs with glucocorticoid treatment has led to the suggested use of "Corticosteroid Responsive Encephalopathy Associated with Autoimmune Thyroiditis" rather than "Hashimoto's encephalopathy" to define this disorder [3].
The treatments described in the literature include glucocorticoids alone, glucocorticoids with levothyroxine and levothyroxine alone, with a good response in $98 \%, 92 \%$ and $67 \%$ respectively [1]. Refractory and persistent cases have been treated with mycophenolate mofetil, azothioprine, cyclophosphamide, plaguenil, methotrexte, IVIG and plasma exchange [7].

Due to an expected increase in recognition in the future, endocrinologists, neurologists and primary care doctors should be aware of the terminology currently used in the literature, and also of the characteristics and the management of the disease [8]. Thyroid dysfunction should be managed as in the absence of encephalopathy [8]. All patients with serum TSH levels 
23.

4. Yoneda M, Fujii A, Ito A, et al. High prevalence of serum autoantibodies against the amino terminal of alpha-enolase in Hashimoto's encephalopathy. J Neuroimmunol 2007;185(1-2):195-200.

5. Gini B, Lovato L, Cianti R, et al. Novel autoantigens recognized by CSF IgG from Hashimoto's encephalitis revealed by a proteomic approach. J Neuroimmunol 2008;196(1-2):153-158.

6. Blanchin S, Coffin C, Viader F, et al. Antithyroperoxidase antibodies from patients with Hashimoto`s encephaopathy bind to cerebellar astrocytes. J Neuroimmunol 2007;192(1-2):13-20.

\section{CONCLUSION}

Hashimoto's Encephalopathy is a diagnosis of exclusion, and should be suspected in every patient with encephalopathy without detectable cause, especially in the setting of an underlying thyroid abnormality.

$* * * * * * * * *$

\section{Author Contributions}

Vasile M Bota - Conception and design, Acquisition of data, Analysis and interpretation of data, Drafting the article, Final approval of the version to be published Dominic F Corrigan - Conception and design, Acquisition of data, Analysis and interpretation of data, Drafting the article, Critical revision of the article, Final approval of the version to be published

\section{Guarantor}

The corresponding author is the guarantor of submission

\section{Conflict of Interest}

Authors declare no conflict of interest.

\section{Copyright}

(C) Vasile M Bota et. al. 2011; This article is distributed under the terms of Creative Commons attribution 3.0 License which permits unrestricted use, distribution and reproduction in any means provided the original authors and original publisher are properly credited. (Please see www.ijcasereportsandimages.com /copyright-policy.php for more information.)

\section{REFERENCES}

1. Chong JY, Rowland LP, Utiger RD. Hashimoto Encephalopathy: Syndrome or Myth? Arch Neurol 2003;60(2):164-171.

2. Mocellin R, Walterfang M, Velakoulis D. Hashimoto's encephalopathy: epidemiology, pathogenesis and management. CNS Drugs 2007;21(10):799-811.

3. Tamagno G, Federspil G, Murialdo G. Clinical and diagnostic aspects of encephalopathy associated with autoimmune thyroid disease (or Hashimoto's encephalopathy). Intern Emerg Med 2006;1(1):15-
7. Marshall GA, Doyle JJ. Long-term treatment of Hashimoto's encephalopathy. J Neuropsychiatry Clin Neurosci 2006;18(1):14-20.

8. Fatourechi V. Hashimoto`s encephalopathy: myth or reality? An endocrinologist`s perspective. Best Pract Res Clin Endocrinol Metab 2005;19(1):53-66. 